\title{
Effects of Schisandra
}

\section{sphenanthera extract on}

the pharmacokinetics of

\section{midazolam in healthy}

\section{volunteers}

\section{Hua-Wen Xin, Xiao-Chun Wu, Qing Li, Ai-Rong Yu \& Lei Xiong \\ Department of Clinical Pharmacology, Wuhan General Hospital of Guangzhou Command, Wuhan,} China

\section{Correspondence}

Dr Hua-Wen Xin, Department of Clinical Pharmacology, Wuhan General Hospital of Guangzhou Command, 627 Wuluo Road, Wuhan, 430070, China.

Tel: + 862768878690

Fax: + 862768878688

E-mail: huawenxin@163.com

\section{Keywords}

CYP3A, healthy volunteers, hydroxymidazolam, midazolam, pharmacokinetics, Schisandra sphenanthera extract

\section{Received}

21 September 2008

Accepted

30 January 2009

\section{WHAT IS ALREADY KNOWN ABOUT} THIS SUBJECT

- Schisandra sphenanthera extract (SchE) and tacrolimus are often co-administered in treating renal and liver transplant recipients in China.

- Our previous study has demonstrated that SchE can increase the oral bioavailability of tacrolimus.

\section{WHAT THIS STUDY ADDS}

- The results of this study show that SchE can markedly increase the blood concentration and oral bioavailability of midazolam in healthy volunteers.

- This finding suggests that SchE may be an inhibitor of CYP3A and is likely to alter the disposition of drugs that are metabolized by CYP3A.

\section{AIMS}

To assess the effect of Schisandra sphenanthera extract (SchE) on the pharmacokinetics of midazolam, a probe drug of CYP3A, and its metabolite 1'-hydroxy midazolam in healthy volunteers.

\section{METHODS}

Twelve healthy male volunteers were orally treated with SchE, three capsules twice daily for 7 days. Pharmacokinetic investigations of oral midazolam administration at $15 \mathrm{mg}$ were performed both before and at the end of the SchE treatment period. The plasma midazolam and 1 '-hydroxy midazolam concentrations were determined by high-performance liquid chromatography-tandem mass spectrometry. Estimated pharmacokinetic parameters before and with SchE were calculated with noncompartmental techniques.

\section{RESULTS}

Following administration of SchE, the average increases (\%) of individual increases in AUC, AUMC and $C_{\max }$ of midazolam were $119.4 \%$ [95\% confidence interval (CI) 83.9, 155.0], 183.4\% (95\% Cl 120.5, 246.2) and $85.6 \%(95 \% \mathrm{Cl} 14.4,156.9)$, respectively $(P<0.01$ or 0.05$)$. On average, there was a $133.3 \%(95 \% \mathrm{Cl} 8.9,257.7)$ increase in midazolam $t_{\max }(P<0.01)$. The average decrease $(\%)$ in $\mathrm{CL} / \mathrm{F}$ was $52.1 \%(95 \% \mathrm{Cl}$ $44.9,59.4)(P<0.01)$. No significant changes were seen in midazolam half-life. After co-administration of SchE, the average increase (\%) in $t_{\max }$ of 1 '-hydroxy midazolam was $150.0 \%(95 \% \mathrm{Cl} 22.2,277.8)(P<0.05)$. No significant differences were observed in the other pharmacokinetic parameters of 1 '-hydroxy midazolam.

\section{CONCLUSIONS}

SchE can markedly increase the oral bioavailability of midazolam in healthy volunteers. SchE is an inhibitor of CYP3A and has a high susceptibility to alter the disposition of drugs metabolized by CYP3A. 


\section{Introduction}

Schisandra sphenanthera extract (SchE) is a prescribed drug rather than a herbal supplement that has been widely used to treat viral and drug-induced hepatitis in China. It has shown that several constituents isolated from S. sphenanthera can interact with CYP3A and/or P-glycoprotein (P-gp) [1-4]. Tacrolimus (FK506) is a widely used immunosuppressive drug in various solid-organ transplantations and is co-medicated with multiple drugs under clinical conditions [5, 6]. SchE and tacrolimus are often co-administered when drug-induced hepatitis occurs in transplant recipients. Tacrolimus is a substrate for both CYP3A and P-gp [7, 8]. Therefore interaction between SchE and tacrolimus may occur when the two drugs are co-administered. Our previous work has demonstrated that SchE treatment can result in a substantial increase in the relative bioavailability of tacrolimus [9]. However, the mechanism of this interaction is still unknown.

Since tacrolimus is primarily metabolized by CYP3A, we aimed to investigate whether SchE increases the bioavailability of tacrolimus by inhibiting CYP3A. The use of select drugs as 'probes' to assess in vivo CYP activity has been the subject of intense interest for over a decade [10]. Midazolam is a benzodiazepine adaptable for preoperative sedation, anxiolysis and anterograde amnesia. Midazolam is metabolized to $1^{\prime}$-hydroxy and 4-hydroxy midazolam by CYP3A4 and CYP3A5 and has been suggested to be an ideal probe for the activity of CYP3A [11-13].

The goal of the current study was to evaluate the effects of SchE on hepatic and intestinal CYP3A catalytic activity. Midazolam was employed in this study as an in vivo probe for CYP3A hepatic and intestinal activity. The effect of SchE on the AUC and other pharmacokinetic parameters of midazolam and the metabolite 1'-hydroxy midazolam was studied in healthy volunteers.

\section{Materials and methods}

\section{Subjects}

Twelve healthy male volunteers, $22.5 \pm 0.9$ years old, 172.6 $\pm 5.0 \mathrm{~cm}$ in height and weighing $63.1 \pm 6.1 \mathrm{~kg}$, participated in the trials. Before entering the study, each subject underwent routine physical examination and laboratory investigations. Laboratory indices included liver and renal function, blood routine and blood glucose. Volunteers were considered to be healthy if physical examination, medical history, and standard biochemical blood tests were normal. Smokers and those taking medication were excluded. Informed consent was obtained according to the Declaration of Helsinki. The study was approved by the Ethics Committee of Wuhan General Hospital, ethics approval no. 2008005.

\section{Trial design and blood sampling}

In the morning of day 1 , each volunteer received $15 \mathrm{mg}$ midazolam (Shanghai Roche Pharmaceuticals Ltd, China) orally along with $150 \mathrm{ml}$ water. Venous blood samples $(2 \mathrm{ml})$ were taken from an indwelling venous catheter into tubes containing heparin sodium at $0,0.25,0.5,1,2,3,4,5$, $6,9,12$ and $24 \mathrm{~h}$ postdose. After last sampling, subjects received three capsules of SchE (also called Wu-Zhi capsule) (Hezheng Pharmaceutical Company, Chengdu, China, each capsule containing $11.25 \mathrm{mg}$ deoxyschizandrin) twice daily for 7 days. On day 9 , subjects were given another single oral dose of $15 \mathrm{mg}$ midazolam, followed by three SchE capsules. The sampling times were the same as on day 1 . On day 16 , venous blood samples were taken to determine liver and renal function, blood routine and blood glucose.

\section{Diet}

Volunteers fasted from midnight until receiving their morning dose of midazolam on day 1 and day 9. Alcohol, caffeine-containing foods and beverages were not allowed from $72 \mathrm{~h}$ before the study until the end of the trial. Subjects received standardized meals at specified times: lunch $4 \mathrm{~h}$ postdose (at about $12.00 \mathrm{~h}$ ) and dinner $10 \mathrm{~h}$ postdose (at about $18.00 \mathrm{~h}$ ) on both midazolam administration days.

\section{Drug and metabolite analysis}

Plasma concentrations of midazolam and 1'-hydroxy midazolam were determined by a liquid chromatographytandem mass spectrometry (LC/MS/MS) method simultaneously. The analysis was carried out on a TSQ Quantum Ultra mass spectrometer (Thermo Finnigan, San Jose, CA, USA) equipped with a Agilent 1200 high-performance liquid chromatography (HPLC) system (Agilent, Munich, Germany).

Plasma samples were assayed for parent midazolam and for $1^{\prime}$-hydroxy midazolam. To $0.5 \mathrm{ml}$ plasma, $50 \mu \mathrm{l}$ internal standard (800 $\mathrm{ng} \mathrm{ml}^{-1}$ tamsulosin), $100 \mu$ methanol : water $(80: 20, \mathrm{v} / \mathrm{v})$ and $100 \mu \mathrm{laOH}\left(1 \mathrm{~mol} \mathrm{I}^{-1}\right)$ were added and then mixed. After the addition of $4 \mathrm{ml}$ hexane:trichloromethane $(1: 1, v / v)$, the samples were shaken for $4 \mathrm{~min}$ and centrifuged. The organic phase was extracted and evaporated to dryness at $40^{\circ} \mathrm{C}$. The residue was dissolved in $100 \mu \mathrm{l}$ of mobile phase, and $10 \mu \mathrm{l}$ was used for analysis with HPLC-MS/MS. Analytes were separated using an inertsil ODS-3, $100 \times 2.1 \mathrm{~mm}$ column with methanol:1\% formic acid $(70: 30)$ as the mobile phase. Midazolam was monitored in positive ion mode with the transition of $\mathrm{m} / \mathrm{z} 326.0$ to $\mathrm{m} / \mathrm{z} 291.0,1^{\prime}$-hydroxy midazolam and tamsulosin with the transition of $\mathrm{m} / \mathrm{z} 342.0$ to $\mathrm{m} / \mathrm{z}$ 324.0 and $\mathrm{m} / \mathrm{z} 409.2$ to $\mathrm{m} / \mathrm{z} 228.0$, respectively. The lower limit of quantification of both midazolam and 1'-hydroxy midazolam was $0.25 \mathrm{ng} \mathrm{ml}^{-1}$. For midazolam a total of six batches, each containing three different concentrations $\left(0.5,50\right.$ and $\left.350 \mathrm{ng} \mathrm{ml}^{-1}\right)$ were analysed, yielding an accu- 
racy ranging from 95.6 to $105.0 \%$ with a coefficient of variation from 5.32 to $8.81 \%$. For $1^{\prime}$-hydroxy midazolam a total of six batches, each containing three different concentrations $\left(0.5,50\right.$ and $\left.350 \mathrm{ng} \mathrm{ml}^{-1}\right)$ were analysed, yielding an accuracy ranging from 95.9 to $103.0 \%$ with a coefficient of variation from 6.72 to $9.32 \%$.

\section{Pharmacokinetic calculations}

The pharmacokinetic parameters included: area under the blood concentration-time curve (AUC), area under the moment curve (AUMC), elimination half life $\left(t_{1 / 2}\right)$, maximum blood drug concentration $\left(C_{\max }\right)$, time to $C_{\max }\left(t_{\max }\right)$, and apparent oral clearance (CL/F). $C_{\max }$ and $t_{\max }$ were determined by visual inspection of the blood concentrationtime curves. The other parameters such as $t_{1 / 2}$ were calculated using the noncompartmental model with Pharmacokinetic Program DAS 2.0 (Chinese Pharmacologic Society, Beijing, China). For the above parameters, a 95\% confidence interval $(\mathrm{Cl})$ for the increase (\%) or decrease (\%) of treatment before SchE compared with that after SchE was estimated. The $90 \% \mathrm{Cl}$ for the ratio of midazolam AUC after SchE to that before SchE was constructed. Drug-drug interaction was concluded if the $90 \% \mathrm{Cl}$ did not fall within the prespecified interval of $80-125 \%$.

\section{Statistical analysis}

Statistical calculations were carried out using SPSS software 10.0 (SPSS Inc., Chicago, IL, USA). AUC and $C_{\max }$ were log transformed prior to analysis with paired Student's t-test.All other parameters were assessed using paired Student's $t$-test. $P<0.05$ was considered to be statistically significant.

\section{Results}

The plasma concentration-time curves of midazolam and its 1'-hydroxy metabolite prior to and following co-administration of SchE in 12 healthy volunteers are shown in Figures 1 and 2. Pharmacokinetic parameters of midazolam and $1^{\prime}$-hydroxy midazolam in 12 healthy volunteers before and after co-administration with SchE are given in Tables 1 and 2. Individual data for the effect of SchE on midazolam AUC are shown in Figure 3.

After co-administration of SchE, the average increases (\%) of individual increases in AUC, AUMC and $C_{\max }$ of midazolam were $119.4 \%(95 \% \mathrm{Cl} 83.9,155.0), 183.4 \%(95 \% \mathrm{Cl}$ $120.5,246.2)$ and $85.6 \%(95 \% \mathrm{Cl} 14.4,156.9)$, respectively $(P$ $<0.01$ or 0.05 ). The $90 \% \mathrm{Cl}$ for the ratio of midazolam AUC after SchE to that before SchE was 191.7,250.1. On average, there was a $133.3 \%(95 \% \mathrm{Cl} 8.9,257.7)$ increase in midazolam $t_{\max }(P<0.01)$. The average decrease $(\%)$ in $C L / F$ was $52.1 \%(95 \% \mathrm{Cl} 44.9,59.4)(P<0.01)$. No significant changes were seen in midazolam half-life.

After co-administration of SchE, the average increases (\%) in $t_{\max }$ of $1^{\prime}$-hydroxy midazolam were $150.0 \%(95 \% \mathrm{Cl}$

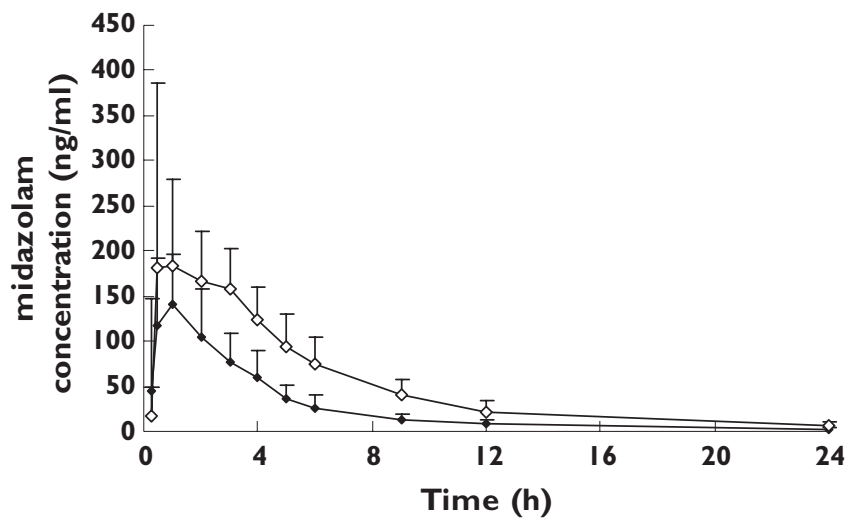

\section{Figure 1}

Mean blood concentration-time curves of midazolam in 12 healthy volunteers before and after co-administration with Schisandra sphenanthera extract (SchE). Before SchE (—४ —); After SchE (—૪—)

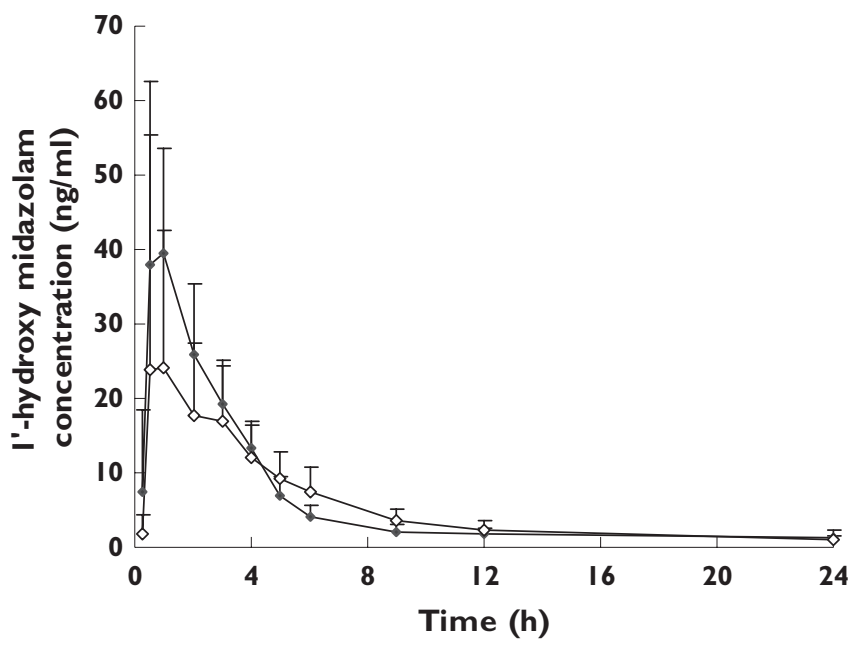

\section{Figure 2}

Mean blood concentration-time curves of $1^{\prime}$-hydroxy midazolam in 12 healthy volunteers before and after co-administration with Schisandra sphenanthera extract (SchE). Before SchE (-৮); After SchE (一๖—)

$22.2,277.8)(P<0.05)$. No significant differences were observed in the other pharmacokinetic parameters of $1^{\prime}$-hydroxy midazolam.

The plasma 1'-hydroxy midazolam/midazolam concentration ratios of $1 \mathrm{~h}$ after midazolam dosing in 12 healthy volunteers before and after co-administration with SchE were $0.28 \pm 0.09$ and $0.12 \pm 0.04$, respectively $(P<0.05)$.

Measurements for hepatic and renal functions and other indices are shown in Table 3. These laboratory indices include serum total bilirubin (TB), direct bilirubin, alanine aminotransferase (ALT), aspartate aminotransferase, urea nitrogen, creatinine ( $\mathrm{Cr}$ ), blood glucose (GLU), white blood cell, red blood cell, haemoglobin $(\mathrm{Hb})$ and platelet. Compared with before co-administration of SchE, the mean TB and $\mathrm{Cr}$ levels with SchE were higher and the mean ALT, GLU 


\section{Table 1}

The average midazolam pharmacokinetic parameters of 12 healthy volunteers before and after co-administration with SchE

\begin{tabular}{|c|c|c|c|c|c|c|}
\hline & $\begin{array}{l}\mathrm{AUC}_{0-24} \\
\left(\mu \mathrm{g} \mathrm{I}^{-1} \mathrm{~h}^{-1}\right)\end{array}$ & $\begin{array}{l}\text { AUMC }_{0-24} \\
\left(\mu \mathrm{g} \mathrm{I}^{-1} \mathrm{~h}^{-1}\right)\end{array}$ & $\begin{array}{l}\mathrm{CL}(\mathbf{s}) \\
\left(\mathrm{h} \mathrm{h}^{-1}\right)\end{array}$ & $\begin{array}{l}T_{1 / 2} \\
\text { (h) }\end{array}$ & $\begin{array}{l}T_{\max } \\
\text { (h) }\end{array}$ & $\begin{array}{l}C_{\max } \\
\left(\mu \mathrm{g} \mathrm{I}^{-1}\right)\end{array}$ \\
\hline \multicolumn{7}{|c|}{ Before SchE } \\
\hline Mean & 577.72 & 2387.52 & 30.87 & 3.39 & 0.81 & 171.35 \\
\hline SD & 226.83 & 1288.89 & 16.71 & 1.04 & 0.47 & 69.84 \\
\hline \multicolumn{7}{|c|}{ After SchE } \\
\hline Mean & $1185.61 * *$ & $6163.42^{* *}$ & $13.77 * *$ & 3.55 & $1.63^{* *}$ & $282.25^{*}$ \\
\hline SD & 319.82 & 2713.08 & 5.75 & 1.13 & 1.17 & 152.18 \\
\hline
\end{tabular}

Compared with before co-administration with SchE, ${ }^{*} P<0.05 ; * * P<0.01$.

\section{Table 2}

The average 1'-hydroxy midazolam pharmacokinetic parameters of 12 healthy volunteers before and after co-administration with SchE

\begin{tabular}{|c|c|c|c|c|c|c|}
\hline & $\begin{array}{l}\text { AUC }_{0-24} \\
\left(\mu \mathrm{I} \mathrm{I}^{-1} \mathrm{~h}^{-1}\right)\end{array}$ & $\begin{array}{l}\text { AUMC }_{0-24} \\
\left(\mu \mathrm{g} \mathrm{I}^{-1} \mathrm{~h}^{-1}\right)\end{array}$ & $\begin{array}{l}\mathrm{CL}(\mathbf{s}) \\
\left(\mathbf{l} \mathbf{h}^{-1}\right)\end{array}$ & $\begin{array}{l}T_{1 / 2} \\
\text { (h) }\end{array}$ & $\begin{array}{l}T_{\max } \\
\text { (h) }\end{array}$ & $\begin{array}{l}C_{\max } \\
\left(\mu \mathrm{g} \mathrm{I}^{-1}\right)\end{array}$ \\
\hline \multicolumn{7}{|c|}{ Before SchE } \\
\hline Mean & 140.86 & 561.37 & 129.74 & 5.59 & 0.75 & 47.85 \\
\hline SD & 69.29 & 290.83 & 67.57 & 3.25 & 0.26 & 23.17 \\
\hline \multicolumn{7}{|c|}{ After SchE } \\
\hline Mean & 129.15 & 677.82 & 134.41 & 4.99 & $1.63^{*}$ & 36.33 \\
\hline SD & 48.74 & 245.96 & 71.57 & 2.14 & 1.17 & 28.05 \\
\hline
\end{tabular}

Compared with before co-administration with SchE, ${ }^{*} P<0.05$.

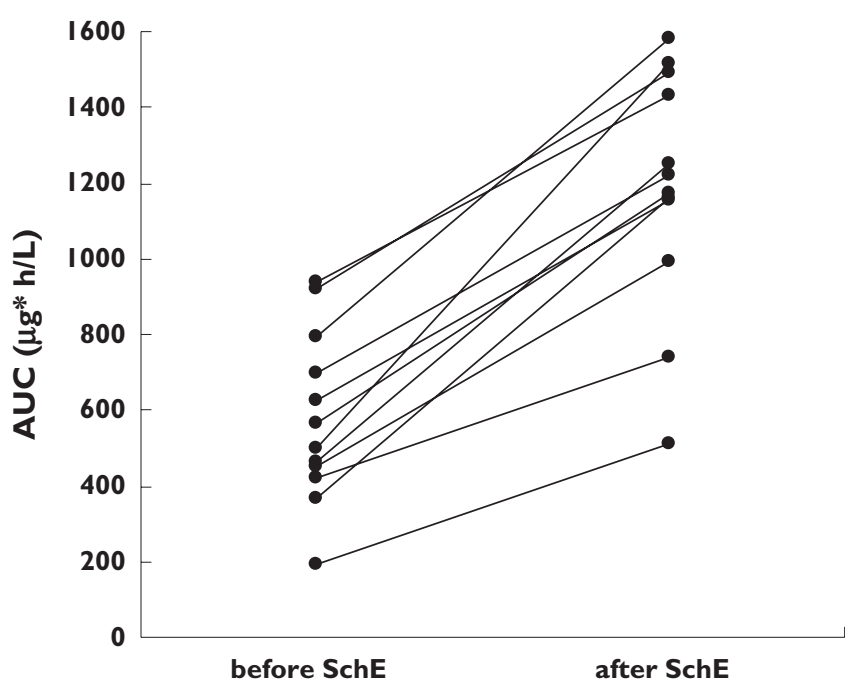

\section{Figure 3}

Individual data for the effect of Schisandra sphenanthera extract (SchE) on midazolam AUC

and $\mathrm{Hb}$ values were lower in the presence of SchE $(P<0.05$ or 0.01$)$, but the values were still within the normal range. No significant changes were observed in the other indices.

\section{Table 3}

Liver function and renal function as well as other indices in 12 healthy volunteers before and after co-administration with SchE (mean \pm SD)

\begin{tabular}{|c|c|c|}
\hline Index & $\begin{array}{l}\text { Before co-administration } \\
\text { with SchE }\end{array}$ & $\begin{array}{l}\text { After co-administration } \\
\text { with SchE }\end{array}$ \\
\hline TB $\left(\mu \mathrm{mol} \mathrm{I}^{-1}\right)$ & $11.97 \pm 3.44$ & $15.20 \pm 6.05^{*}$ \\
\hline DB $\left(\mu \mathrm{mol} \mathrm{I}^{-1}\right)$ & $3.30 \pm 0.95$ & $2.53 \pm 1.35$ \\
\hline ALT $\left(\mathrm{UI}^{-1}\right)$ & $18.58 \pm 12.31$ & $13.83 \pm 7.55^{*}$ \\
\hline AST $\left(\mathrm{UI}^{-1}\right)$ & $18.42 \pm 4.56$ & $17.75 \pm 5.55$ \\
\hline BUN (mmol l-1) & $3.85 \pm 0.93$ & $3.97 \pm 0.75$ \\
\hline $\mathrm{Cr}\left(\mu \mathrm{mol} \mathrm{I} \mathrm{I}^{-1}\right)$ & $72.83 \pm 9.54$ & $77.53 \pm 11.87 *$ \\
\hline GLU (mmol l-1) & $5.00 \pm 0.33$ & $4.41 \pm 0.33^{* *}$ \\
\hline WBC $\left(\times 10^{9} \mathrm{I}^{-1}\right)$ & $5.68 \pm 0.67$ & $5.96 \pm 0.70$ \\
\hline $\operatorname{RBC}\left(\times\left. 10^{12}\right|^{-1}\right)$ & $4.83 \pm 0.26$ & $4.74 \pm 0.36$ \\
\hline $\mathrm{Hb}\left(\mathrm{gl}^{-1}\right)$ & $148.50 \pm 10.36$ & $144.67 \pm 9.28^{*}$ \\
\hline PIt $\left(\times\left. 10^{9}\right|^{-1}\right)$ & $230.33 \pm 35.14$ & $224.42 \pm 32.94$ \\
\hline
\end{tabular}

Compared with before co-administration with $\mathrm{SchE},{ }^{*} P<0.05$; ${ }^{*} P<0.01$. TB, total bilirubin; DB, direct bilirubin; ALT, alanine aminotransferase; AST, aspartate aminotransferase; BUN, urea nitrogen; $\mathrm{Cr}$, creatinine; GLU, blood glucose; $\mathrm{Hb}$, haemoglobin; Plt, platelets; RBC, red blood cells; WBC, white blood cells.

During administration of midazolam alone, all subjects felt drowsy about $30 \mathrm{~min}$ after administration of midazolam and then went to sleep. They woke up 2-4 h later. Besides drowsiness, they reported a total of 16 adverse events, which were either mild or moderate in intensity. These symptoms were headache $(n=2)$, dizziness $(n=4)$ and fatigue $(n=10)$. During administration of SchE alone for 7 days, no adverse events were reported. During concomitant administration of SchE and midazolam, all volunteers also went to sleep about 30 min after orally taking midazolam. Their sleep time was about 3-5 $\mathrm{h}$ longer than in the period of administration of midazolam alone. Moreover, a total of 22 adverse events were reported. These adverse events included headache $(n=3)$, dizziness $(n=7)$, fatigue $(n=11)$ and postural hypotension $(n=1)$. All adverse events resolved completely within $24 \mathrm{~h}$ and none resulted in withdrawal from the study.

\section{Discussion}

The combined use of several drugs may produce interactions based on the pharmacological effects of individual drugs. In addition to interactions between synthetic drugs, drug-herbal medicine or supplement interactions have also been observed [14]. Some reported studies on herbaldrug interactions have revealed that the extract of herbal supplements including ginkgo leaf, echinacea, and milkthistle inhibited CYP3A4 activity in human liver microsomes [15-17]. Interaction between SchE and tacrolimus has been reported in our previous study [9]. The present study was conducted to clarify whether SchE may interact with tacrolimus via CYP3A. Our results have shown that 1 week's ingestion of SchE caused significant 
increases in AUC, $C_{\max }$ and $t_{\max }$ and declines in $\mathrm{CL} / \mathrm{F}$ of midazolam, whereas there was no change in the elimination half-life. Since the $90 \% \mathrm{Cl}$ for the AUC was much higher than the prespecified interval of $0.8,1.25$, the interaction between SchE and midazolam must be considered to be clinically significant.

One study has shown that grapefruit juice could increase the bioavailability of midazolam and led to a $79 \%$ increase in $t_{\max }$ of midazolam and a $105 \%$ increase in $t_{\max }$ of 1 '-hydroxy midazolam [18]. In this study, $t_{\max }$ of midazolam and $1^{\prime}$-hydroxy midazolam was also significantly increased by pretreatment of SchE. The increase in $t_{\max }$ of $1^{\prime}$-hydroxy midazolam should be caused by the increase in $t_{\max }$ of midazolam. However, the exact mechanism for the increase in $t_{\max }$ of midazolam is unclear and should be studied further.

Several studies have demonstrated that there was no change in the elimination half-life of midazolam, whereas AUC and $C_{\max }$ were significantly changed $[17,19]$. It has also been reported that even though there was no change in $t_{1 / 2}$ of midazolam, inhibition of hepatic and/or intestinal CYP3A was considered [17]. Our present study had similar results. Therefore, although no change in $t_{1 / 2}$ of midazolam was found in our study, the inhibition of hepatic and/or intestinal CYP3A by SchE was still considered. According to the classification system of CYP3A inhibitors as in the September 2006 Food and Drug Administration guidance on drug interaction studies, a moderate inhibitor is one that causes a two or more but less than fivefold increase in the AUC values in clinical evaluations. Based on the results of this study, we can conclude that SchE is a moderate CYP3A inhibitor.

It has been reported that the plasma $1^{\prime}$-hydroxy midazolam/midazolam concentration ratio of 0.5 or $1 \mathrm{~h}$ after midazolam administration can be used to predict CYP3A activity [20,21]. The use of a single blood sample to predict changes in CYP3A activity is particularly useful and important in a drug interaction study. In the present study, the ratio mentioned above after co-administration with SchE was decreased significantly. This result further demonstrates that SchE can inhibit the CYP3A activity and also indicates that a single blood sample at $1 \mathrm{~h}$ after midazolam dosing can be used to confirm CYP3A activity.

After co-administration with SchE, the sleep time in 12 volunteers became longer and the adverse effects increased, although these symptoms were part of the expected adverse event profile of midazolam. The enhanced sedative effect should be due to a considerable increase in the blood concentration of midazolam.

The effects of SchE on the function of P-gp may also be important when considering the mechanism of the changes in the pharmacokinetics of orally administered drugs during the absorption process, but it can be excluded in this case, since midazolam is not a substrate for P-gp [22]. Thus, the enhanced oral bioavailability of midazolam caused by SchE could result from the decreased activity of CYP3A. It has been reported that the relationship between the disposition of midazolam administered orally and hepatic CYP3A content is weaker than that after intravenous administration, indicating the importance of the contribution of intestinal CYP3A to the in vivo disposition of midazolam administered orally [23]. Therefore, the increased bioavailability of midazolam by SchE may mainly come from the decreased activity of intestinal CYP3A.

In fact, one study has indicated that Schisandra fruit components could inhibit the activity of CYP3A4 in vitro [4]. That study was conducted to identify Schisandra fruit components having inhibitory effects on CYP3A4 by surveying the effect on human liver microsomal erythromycin $\mathrm{N}$-demethylation activity. Known components of Schisandra fruit, gomisins $B, C, G$ and $N$ and gamma-shizandrin, showed inhibitory effects on $\mathrm{N}$-demethylation activity. Among these components, gomisin C displayed the most potent and competitive inhibitory effect. Furthermore, the inhibitory effect of gomisin $C$ was stronger than that of ketoconazole, a known potent CYP3A4 inhibitor. The human liver microsomal erythromycin $\mathrm{N}$-demethylation activity inactivated by gomisin $\mathrm{C}$ did not recover on dialysis of the microsomes. These results indicate that gomisin C is a mechanism-based inhibitor that not only competitively inhibits but irreversibly inactivates CYP3A4. Our results in vivo are consistent with the above study in vitro [4]. However, which components of SchE play important roles in reduced CYP3A activity is still unclear.

The inhibition of CYP3A may result in enhanced blood and tissue concentrations of CYP3A substrates, and caused toxicity. Our results have shown the possible interaction between SchE and medicines metabolized by CYP3A. Thus, frequent monitoring of blood concentration and dose adjustments of CYP3A substrates are highly recommended when co-administration with SchE is unavoidable.

In conclusion, the results of this study have shown that SchE can markedly increase the blood concentration and oral bioavailability of midazolam in healthy men. This finding suggests that SchE is an inhibitor of CYP3A and has a high susceptibility to alter the disposition of drugs metabolized by CYP3A (e.g. tacrolimus).

\section{Competing interests}

None declared.

This research was supported by the medical research foundation of Hubei Province in China.

\section{REFERENCES}

1 Madgula VL, Avula B, Choi YW, Pullela SV, Khan IA, Walker LA, Khan SI. Transport of Schisandra chinensis extract and its biologically-active constituents across Caco- 2 cell 
monolayers - an in-vitro model of intestinal transport. J Pharm Pharmacol 2008; 60: 363-70.

2 Wan CK, Zhu GY, Shen XL, Chattopadhyay A, Dey S, Fong WF. Gomisin A alters substrate interaction and reverses P-glycoprotein-mediated multidrug resistance in HepG2-DR cells. Biochem Pharmacol 2006; 72: 824-37.

3 Sun M, Xu X, Lu Q, Pan Q, Hu X. Schisandrin B: a dual inhibitor of $P$-glycoprotein and multidrug resistance-associated protein 1 . Cancer Lett 2007; 246: 300-7.

4 Iwata H, Tezuka Y, Kadota S, Hiratsuka A, Watabe T. Identification and characterization of potent CYP3A4 inhibitors in Schisandra fruit extract. Drug Metab Dispos 2004; 32: 1351-8.

5 Bowman LJ, Brennan DC. The role of tacrolimus in renal transplantation. Expert Opin Pharmacother 2008; 9: 635-43.

6 Patel JK, Kobashigawa JA. Tacrolimus in heart transplant recipients: an overview. BioDrugs 2007; 21: 139-43.

7 Iwasaki K. Metabolism of tacrolimus (FK506) and recent topics in clinical pharmacokinetics. Drug Metab Pharmacokinet 2007; 22: 328-35.

8 Saeki T, Ueda K, Tanigawara Y, Hori R, Komano T. Human P-glycoprotein transports cyclosporin A and FK506. J Biol Chem 1993; 268: 6077-80.

9 Xin HW, Wu XC, Li Q, Yu AR, Zhu M, Shen Y, Su D, Xiong L. Effects of Schisandra sphenanthera extract on the pharmacokinetics of tacrolimus in healthy volunteers. $\mathrm{Br} \mathrm{J}$ Clin Pharmacol 2007; 64: 469-75.

10 Watkins PB. Noninvasive tests of CYP3A enzymes. Pharmacogenetics 1994; 4: 171-84.

11 Rogers JF, Rocci ML Jr, Haughey DB, Bertino JS Jr. An evaluation of the suitability of intravenous midazolam as an in vivo marker for hepatic cytochrome P4503A activity. Clin Pharmacol Ther 2003; 73: 153-8.

12 Lee Jl, Chaves-Gnecco D, Amico JA, Kroboth PD, Wilson JW, Fyre RF. Application of semisimultaneous midazolam administration for hepatic and intestinal cytochrome P450 3 A phenotyping. Clin Pharmacol Ther 2002; 72: 718-28.
13 Kim JS, Nafziger AN, Tsunoda SM, Rocci ML Jr, Wilkinson GR, Greenblatt DJ, Bertino JS Jr. Limited sampling strategy to predict AUC of the CYP3A phenotyping probe midazolam in adults: application to various assay techniques. J Clin Pharmacol 2002; 42: 376-82.

14 Yue QY, Bergquist C, Gerden B. Safety of St. John's wort (Hypericum perforatum). Lancet 2000; 355: 576-7.

15 Von Moltke LL, Weemholff JL, Bedir E, Khan IA, Harmatz JS, Goldman P, Greenblatt DJ. Inhibition of human cytochrome P450 by components of Ginkgo biloba. J Pharm Pharmacol 2004; 56: 1039-44.

16 Yale SH, Glurich I. Analysis of inhibitory potential of Ginkgo biloba, Echinacea purpurea, and Serenoa repens on metabolic activity of cytochrome P450 3A4,2D6, and 2C9. J Altern Complement Med 2005; 75: 433-9.

17 Matsuda K, Nishimura Y, Kurata N, Iwase M, Yasuhara H. Effects of continuous ingestion of herbal teas on intestinal CYP3A in the rat. J Pharmacol Sci 2007; 103: 214-21.

18 Kupferschmidt HH, Ha HR, Ziegler WH, Meier PJ, Krähenbühl S. Interaction between grapefruit juice and midazolam in humans. Clin Pharmacol Ther 1995; 58: 20-8.

19 Nies AS, Shand DG, Willkinsin GR. Altered hepatic blood flow and drug disposition. Clin Pharmacokinet 1976; 1: 135-55.

20 Thummel KE, Shen DD, Podoll TD, Kunze KL, Trager WF, Hartwell PS, Raisys VA, Marsh CL, McVicar JP, Barr DM. Use of midazolam as a human cytochrome P4503A probe: I: in vitro-in vivo correlations in liver transplant patients. J Pharmacol Exp Ther 1994; 271: 549-56.

21 Zhu B, Ou-Yang DS, Cheng ZN, Huang SL, Zhou HH. Single plasma sampling to predict oral clearance of CYP3A probe midazolam. Acta Pharmacol Sin 2001; 22: 634-8.

22 Kim RB, Wandel C, Leake B, Cvetkovic M, Fromm MF, Dempsey PJ, Roden MM, Belas F, Chaudhary AK, Roden DM, Wood AJ, Wilkinson GR. Interrelationship between substrates and inhibitors of human CYP3A and P-glycoprotein. Pharm Res 1999; 16: 408-14.

23 Wandel C, Bocker RH, Bohrer H, deVries JX, Hofmann W, Walter K, Kleingeist B, Neff S, Ding R, Walter-Sack I, Martin E. Relationship between hepatic cytochrome P450 3A content and activity and the disposition of midazolam administered orally. Drug Metab Dispos 1998; 26: 110-4. 